\title{
Microsurgical Treatment of Intracranial Aneurysms: Report of a Series of Cases in a Single Cuban Hospital
}

\begin{abstract}
Angel J esus Lacerda Gallardo*
Doctor of Medical Science, Titular Professor, Titular

Investigator. Diploma in Adult Intensive Care. Member of the Vascular Surgery Chamber of the Cuban Society of Neurology and Neurosurgery, Cuba

*Corresponding author: Dr. C. Angel J esus Lacerda Gallardo, Professor of Neurosurgery, Roberto Rodríguez Hospital, Morón, Ciego de Ávila, Cuba
\end{abstract}

Received: April 30, 2018; Accepted: J une 05, 2018; Published: J une 21, 2018

\begin{abstract}
Introduction: Over various decades, microsurgery has been the most used method for the treatment of intracranial aneurysms, but in the beginning of $90 \mathrm{~s}$, the improvement in endovascular treatment technique informed by Guglielmi, and after that, the improvement of materials used for the obliteration represented a new era in the treatment of these patients and a controversy for the search of an ideal method which is maintained till nowadays.
\end{abstract}

Method: A descriptive study was done with all the patients admitted in the neurosurgery department of Roberto Rodriguez hospital in Moron, Ciego de Avila, Cuba, who presented the diagnosis of intracranial aneurysm and were intervened with the microsurgical technique, excluding the aneurysm from circulation, in the period between January of 1997 and December of 2016.

Results: 170 patients were studied, of which 167 (98.24\%) were found with aneurysms in the anterior circulation and only $3(1.76 \%)$ in the posterior circulation. A total of 210 aneurismal sacs were intervened, of which 133 (63.33\%) were ruptured and 77 (36.67\%) were not ruptured. A $74.11 \%$ of cases recovered without any type of symptoms or sequelae and the mortality was of $1.76 \%$.

Conclusions: The microsurgery is a procedure with high rate of efficiency for the treatment of intracranial aneurysms in our setting, till when another treatment method can be implemented, such as the endovascular treatment method which is widely used in the world

Keywords: Intracranial aneurysms; Microsurgery; Treatment

\section{Introduction}

It is calculated that the risk of suffering from intracranial aneurysm for human being is 1 to $2 \%$ [1], $80 \%$ of patients with intracranial aneurysms present with subarachnoid hemorrhage (SAH), which incidence varies considerably from one geographical area to another, it is estimated at 2 cases among 100000 habitants in China and 22.5/100000 in Finland [2]. In USA 14.5/100000 admissions were reported due to this cause in the year 2003 [3].

The principal objective of intracranial aneurysm treatment is to exclude the aneurysm from the circulation; this can be achieved through two ways, microsurgical treatment or endovascular obliteration.

During various decades microsurgery has been the most used method, but in the beginning of 90 s, the improvement in endovascular treatment technique informed by Guglielmi, and after that, the improvement of materials used for the obliteration, represented a new era in the treatment of these patients and a controversy for the search of an ideal method, which is maintained till nowadays [4-6].

The International Subarachnoid Aneurysm Trial (ISAT) [4], was published in 2002. In that trial, the coil-treated cohort had better clinical outcomes after 1 year of follow-up compared with patients who had undergone surgical clipping. However, concerns have persisted regarding the applicability of ISAT, which excluded almost
$80 \%$ of eligible aneurysms from the study population. The Barrow Ruptured Aneurysm Trial (BRAT) was published in 2013 [5], in that study the outcomes of all patients assigned to coil embolization showed a favorable $5.8 \%$ absolute difference compared with outcomes of those assigned to clip occlusion, although this difference did not reach statistical significance $(\mathrm{p}=0.25)$. Patients in the clip group had a significantly higher degree of aneurysm obliteration and a significantly lower rate of recurrence and retreatment. In post hoc analysis examining only anterior circulation aneurysms, no outcome difference between the 2 treatment cohorts was observed at any recorded time point.

In the year 2017, Bender, et al. [6] published an article in which they revised a database that had information about the patients that were admitted due to SAH during the time between the year 1991 and 2016, with 1306 patients obtainable among 1562 who suffered from the disease, in which it is found that $72 \%$ of the cases were treated with microsurgery, $22 \%$ of the patients were treated with endovascular treatment and $5.7 \%$ were not treated. Also it is revealed that there is an exponential increment per quinquennium of the latter procedure with its percentage reaching $41.9 \%$ between the years 2012 and 2016, which shows that many neurosurgeons prefer the endovascular modality. However, an assay that was published recently, in which 104 patients with the diagnosis of aneurysms that were not ruptured were studied, 48 were treated with microsurgery and 56 with the endovascular technique, the study concluded that 


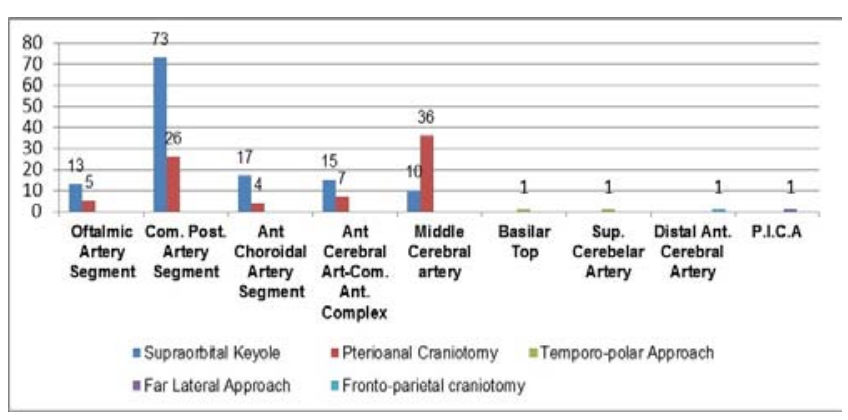

Figure 1: Relation between aneurysms location and the surgical approach.

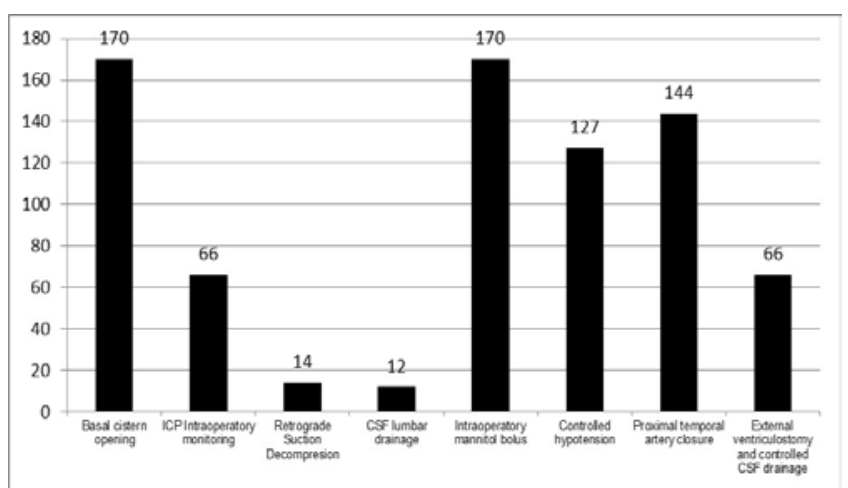

Figure 2: Adyuvant maneuvers.

there were no significant differences when it comes to morbidity and mortality as both procedures are compared [7].

The objective of the current report is to spread the experience acquired for more than 20 years by the neurosurgery department of the Roberto Rodriguez provincial hospital with the use of microsurgical obliteration of intracranial aneurysms.

\section{Method}

This is a descriptive study that includes all the patients admitted to the neurosurgery department, that presented a diagnosis of intracranial aneurism and who were intervened with the microsurgery technique in order to exclude the aneurysms from the circulation, in the period between January 1997 and December 2016.

On their arrival at the emergency department, all the patients were treated according to the designated algorithms for the treatment of hemorrhagic cerebrovascular disease in the hospital and were admitted to the critical care units (Intermediate care and intensive care units), depending on their neurologic state at the moment of admission, determined using the Word Federation of Neurologic Surgeons (WFNS) scale [8] and the Intracerebral Hemorrhage Score (ICH score) in case if it was accompanied by the intraparenchymal hemorrhage [9].

To all the patients, the vascular opacification imaging investigations through cerebral angiography of four vessels, Multi slice-Angio- Computerized axial tomography (Multi slice Angio-CT) or Angio magnetic resonance imaging were done. The results were evaluated by a multidisciplinary team made of at least two specialists in neurosurgery and one specialist in neuroradiology. The presence of
Table 1: General characteristic.

\begin{tabular}{|c|c|c|c|}
\hline \\
\hline Vari & & No & $\%$ \\
\hline \multirow{6}{*}{ WFNS Scale } & Grade 0 & 24 & 14,11 \\
\hline & Grade I & 48 & 28,24 \\
\hline & Grade II & 42 & 24,71 \\
\hline & Grade III & 46 & 27,06 \\
\hline & Grade IV & 7 & 4,12 \\
\hline & Grade V & 3 & 1,76 \\
\hline \multirow{2}{*}{ Aneurysms number } & Single & 149 & 87,65 \\
\hline & Multiple & 21 & 12,35 \\
\hline \multirow{4}{*}{ Size of the Sacs } & Small & 60 & 28,57 \\
\hline & Middle & 100 & 47,62 \\
\hline & Large & 28 & 13,33 \\
\hline & Giants & 22 & 10,48 \\
\hline \multirow{3}{*}{ Morphology of the Sacs } & Saculars & 186 & 88,57 \\
\hline & Multilobulates & 22 & 10,48 \\
\hline & Fusiform & 2 & 0,95 \\
\hline \multirow{2}{*}{ Condition of the Sacs } & Rupture & 133 & 63,33 \\
\hline & Un rupture & 77 & 36,67 \\
\hline \multirow{3}{*}{ Surgical time } & 72 hours & 10 & 5,88 \\
\hline & 73 hours 11 days & 41 & 24,12 \\
\hline & More than 11 days & 119 & 70 \\
\hline \multirow{3}{*}{ Surgical treatment } & Clipped & 182 & 86,67 \\
\hline & Reinforced & 21 & 10 \\
\hline & Trapped & 7 & 3,33 \\
\hline
\end{tabular}

at least one aneurysm was considered an essential condition to decide the surgical treatment. The surgical timing depended completely on this condition.

The information was obtained from the questionnaire and clinical files and passed to a database created by the author using the $15^{\text {th }}$ version of Windows SPSS system.

The considered variables were: Age: which was divided in groups of 18-30 years, 31-50, 51-60 and more than 60 years. Sex: Male or Female. Skin color: Whites, blacks, mixed race and brown. Provenance: The cases were divided in nine categories depending on the municipality of the province from which they came. Clinical state on admission: Was determined using the WFNS scale [8]. On admission and follow up results of neurological imaging. Through the simple brain CT scan on admission and subsequent investigations, the presence of intracranial blood was evaluated, according to the classification of Columbia (Fisher's modified) [10] Vascular opacification imaging: The aneurismal sacs were classified in micro aneurysms, small aneurysms, median aneurysms, big aneurysms and gigantic ones, also were divided according to their number in unique and multiple aneurysms, and distributed according to their localization, the ones in the anterior segment and posterior segment of the Willis' circle. Complications: Were divided into preoperatories, Tran's operatories and post operatories. Results: Were evaluated using the modified Rankin scale for the results [10]. Some variables were correlated in order to get to more precise conclusions. 
The non parametric Chi square goodness of fit test is used to evaluate the hypothesis about the relationship between the two variables. The values of $\mathrm{p} \leq 0.05$ are considered to be significant. The results are expressed in figures so that they can be well analyzed and comprehended.

\section{Results}

170 patients were studied of which 167 (98.24\%) had aneurysms in the anterior circulation and only $3(1.76 \%)$ had in the posterior circulation. A total of 210 aneurismal sacs were handled, of which 133 (63.33\%) were ruptured and 77 (36.64\%) were not ruptured. The general characteristics of the sample are shown in Table 1.

For the imaging diagnosis, cerebral pan angiogram was used in 91 cases (53.53\%) angio multi slide computerized tomography was used in 76 cases $(44.71 \%)$ and angio magnetic resonance imaging was used in 3 patients $(1.76 \%)$

The topographic distribution of the aneurismal sacs was as follows: Ophthalmic artery segment 18 (8.57\%), posterior communicating artery segment $99(47.14 \%)$, anterior choroid artery segment 21 (10\%) medial cerebral artery $46(21.90 \%)$ the arterial complex of anterior communicating and anterior cerebral artery $1(0.48 \%)$ and the postero inferior cerebellar artery $1(0.48 \%)$

Most patients were found to be between grade I and III inclusive of the WFNS classification at the moment of surgery, 136 patients (80\%), according to their number, the predominant ones were single aneurysms, aneurysms of the median size and those ones with saccular morphology. A considerable number of sacs were ruptured and most of the patients, 160 (94.12\%) were operated on in the intermediate or late phase of their evolution. Most of the sacs were clamped and excluded from the circulation.

The lesions that were associated with subarachnoid hemorrhage were: Intraventricular hemorrhage in 10 patients (5.88\%), cerebral infarction in 7 patients $(4.12 \%)$ intraparenchyma hemorrhage in 5 patients $(2.94 \%)$ hydrocephaly in 5 patients $(2.94 \%)$, there were also the simultaneous presence of arteriovenous malformation in 3 cases $(1.76 \%)$, chronic subdural hematoma in $1(0.59 \%)$, which lead to the total of 31 patients with associated lesions, which represented $18.24 \%$ of the series.

The surgical corridors used were related to the localization of the aneurismal sacs, the supraorbitary keyhole predominated $128(60.95 \%)$ and the aneurysms that are found on the posterior communicating segment of the supraclinoid carotid artery (Figure 1).

Adjuvant procedures to facilitate subarachnoid dissection of the mother artery and the aneurismal neck are expressed in Figure 2.

Complications were divided into pre operatories, trans operatories, and post operatories. Among the pre operatories, the most frequent ones were vasospasm without infarction $14(8.23 \%)$ and cerebral infarction $12(7.06 \%)$. Also hydrocephaly was present in 7 patients (4.12\%), intraparenchyma hemorrhage in 5 patients $(2.94 \%)$ as well as second hemorrhage in 1 patient $(0.59 \%)$ and chronic subdural hematoma in 1 patient $(0.59 \%)$. The trans operatory complications were cerebral edema in 12 patients $(7.06 \%)$ and hemorrhage in 6 patients (3.53\%). Among the post operatory complications there were 7 patients with hydrocephaly (4.12\%), post surgical vasospasm in 5

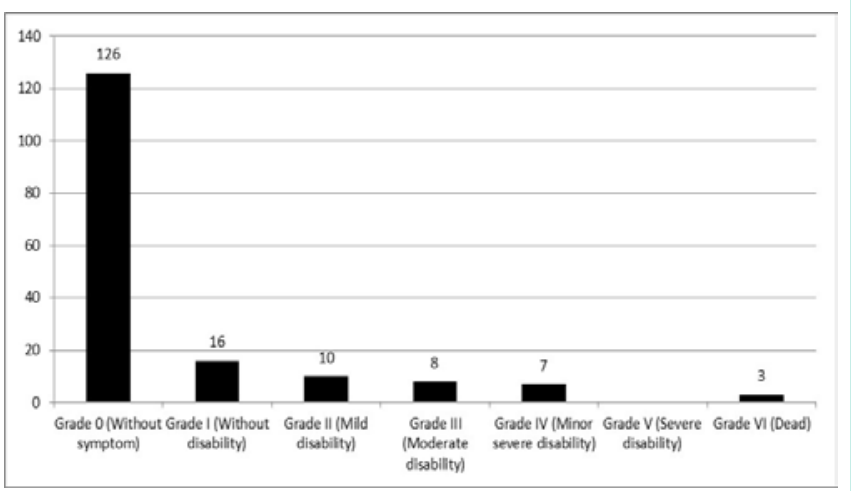

Figure 3: Results. Rankin Modified Scale.

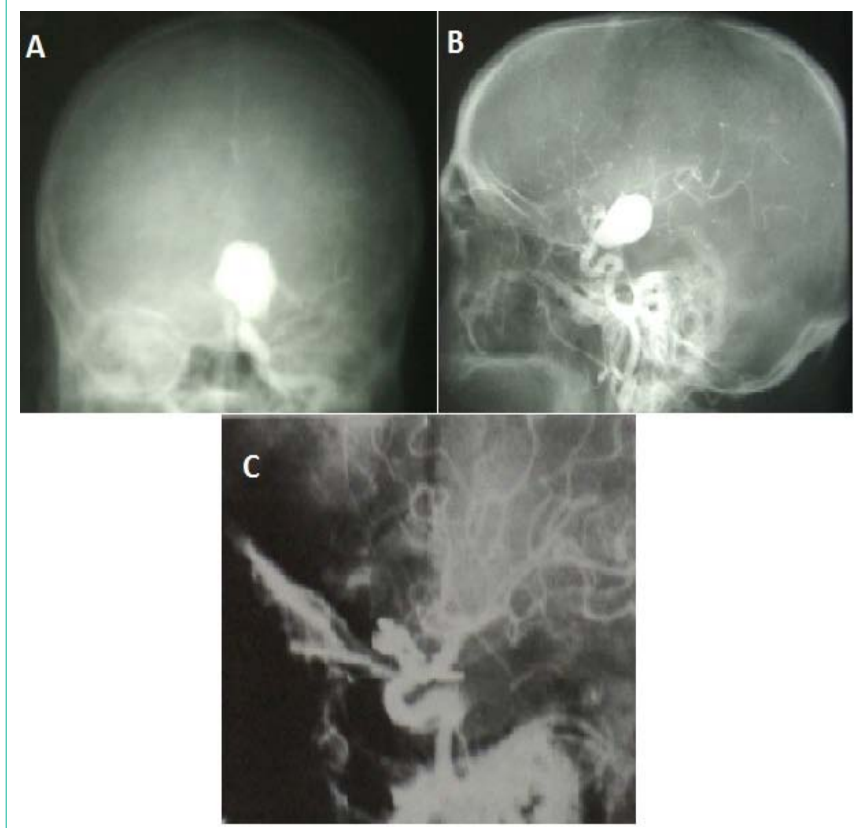

Figure 4: Arteriographic sequence of a big aneurysms located at left posterior communicating segment. a) Pre surgical AP view. b) Left lateral presurgical view. c) Left lateral post surgical view with sac circulatory exclusion

patients (2.94\%) hydro electrolytic imbalance in 5 (2.94\%) acid base imbalance in 2 (2.94\%), infection of surgical wounds in 2 patients (2.94\%) 1 patient with acute pulmonary edema $(0.59 \%)$ and 1 with acute myocardial infarction $(0.59 \%)$

The results are expressed in Figure 3, where the predominance of Grade 0 patients or patients without symptoms can be seen; also the mortality rate of $1.76 \%$ is expressed for the series.

\section{Discussion}

The exclusion from the circulation through microsurgical procedures has been the only form of definitive treatment for ruptured and unruptured aneurysms for more than 20 years at Roberto Rodriguez hospital in Ciego de Avila (Figure 4).

In this series of 170 patients with 210 aneurismal sacs handled, only 2 cases (1.18\%) required a new procedure after being intervened surgically, one of them for showing the growth of aneurismal 
remaining, in the aneurysm of the anterior communicating artery after 2 years from the time when the initial operation was done in another institution of our country and the other patient required an endovascular procedure after trying to clamp the aneurismal sac of the left ophthalmic artery segment, which could not be done due to the presence of hemorrhage before reaching the area, also the patient had other two micro aneurysms in the anterior circulation which were handled conservatively. The incidence of aneurismal remainings or new aneurysms in our series was below the one informed by Burckhardt JK, et al. [11] who had an incidence of $4.6 \%$.

The predominance of aneurysms with the size bigger than $7 \mathrm{~mm}$ and the localization in the posterior communicating artery segment might have probably impacted in the high frequency of aneurismal ruptures. Since the publication of the international study about unruptured aneurysms (ISUIA) [12], it is known that the risk to rupture for 5 years is $0 \%$ for the sacs with a diameter less than $7 \mathrm{~mm}$, $2.6 \%$ for the ones with diameter between 7 to $12 \mathrm{~mm}, 14.5 \%$ for the ones that diameter ranges between $13 \mathrm{~mm}$ and $24 \mathrm{~mm}$ and $40 \%$ for the aneurysms with a diameter of $25 \mathrm{~mm}$ or more, this explains the high rate of rupture in this series. In the ISUIA, the aneurysms of the posterior communicating artery were put in the same group with aneurysms of the posterior circulation as it is related to the risk of rupture, after being considered that the aneurysms with the same size in the same region had the risk to rupture that was superior as compared to the rest of the regions [13].

The selection of the surgical corridor used in relation to the topography and projection of the aneurismal sac is an aspect of vital importance in order to achieve posterior subarachnoid dissection and clamping of the aneurismal neck in a successful way. This series shows the wide experience acquired by the author with use of supra orbital keyhole, in its supercilia, transciliar and fronto lateral variants when handling aneurysms that are found in the anterior segment of Willis cycle, excluding aneurysms located at middle cerebral artery which were approached through a pterion al craniotomy. This experience is well grounded in the comparative studies between different craniotomies, in the spatial analysis of the intracranial cavity and the application of the optic principles, which have guaranteed the use of the corridor in an efficient way and accomplishing the surgical objectives that were put for each patient [14]. The use of endoscope as an auxiliary instrument in this type of corridor (the one used in this series) have facilitated the development of the procedure in the last four decades [14,15], as well as the use of other techniques such as intraoperative angiography with indocyanine green $[16,17]$, which we do not have in our hospital.

The use of adjuvant methods to facilitate the cerebral retraction, subarachnoid dissection, the dissection of vascular structures and their osteo neural relations in the base of the cranium till reaching the aneurismal sac, was a usual practice during surgical operations in the series, and it helped for the adequate dissection and posterior clamping of the aneurismal neck.

The opening and drainage of cerebrospinal fluid in the opt carotid cistern was done in all the cases, combined with the use of mannitol, a conduct that lead to the necessary relaxation of the cerebral parenchyma, allowing the retraction and exposition of neurovascular structures of the base of the cranium. These maneuvers were enhanced with the intermittent drainage of cerebrospinal fluid through the functional ventriculostomy to the exterior, using a catheter that was put in the lateral ventricle or through the catheter for continuous drainage of cerebrospinal fluid that is put in the subarachnoid space of the lumbar column. Also the ventriculostomy was used to monitor intracranial pressure and the cerebral retraction pressure, trying to maintain it around $20 \mathrm{mmHg}$, also intermittent retraction was done, both maneuvers had the objective of avoiding ischemic lesions in the brain cortex which happen as a result of cerebral retraction frequently.

The temporal closure of the mother artery in the final phase of aneurismal neck dissection before definitive clamping is done frequently by majority of vascular neurosurgeons. In this series, as a cerebral protection measure, the cocktail that contained $100 \mathrm{ml}$ of $20 \%$ mannitol, $500 \mathrm{mg}$ of methylprednisolone and $600 \mathrm{mg}$ of ascorbic acid, was administered 20 minutes prior to the temporal closure, this measure was accompanied with the indication of controlled hypotension obtained through the use of nitroglycerine or sodium nitroprusside. The closure was maintained for a minimum of 5 minutes and a maximum of 20 minutes.

In more than half of the patients with gigantic aneurisms, which were those found in the paraclinoid segment, we used the technique of retrograde suction and decompression so as to allow the "deflation" of aneurismal sac and make it possible for the dissection of its neck and posterior clamping.

The results that were obtained in this series, evaluated using the Rankin modified scale, shows the high efficacy of microsurgical treatment for the intracranial aneurysms in our setting in which a big number of patients were discharged without any type of sequelae (74.11\%) and the mortality was of $1.76 \%$

This way we can conclude that the microsurgical treatment for intracranial aneurisms is a procedure with high rate of efficiency, which represents the principal way of solving a serious health problem for the patients suffering from intracranial aneurisms till when other methods will be disponible to be implemented, such as the endovascular treatment that is widely used in the world $[4,5,18$ 20], for which we already have experience in our country.

\section{Acknowledgment}

Thanks to Dr. Paschal Edes Songoro for his collaboration in the revision and translation of this manuscript into the English language.

\section{References}

1. Brown RD Jr, Broderick JP. Unruptured intracranial aneurysms: epidemiology,natural history, management options, and familial screening. Lancet Neurol. 2014; 13: 393-404.

2. Lawton MT, Edward Vates G. Subarachnoid Hemorrhage. N Engl J Med 2017; 377: 257-266.

3. Shea AM, Reed SD, Curtis LH, Alexander MJ, Villani JJ, Schulman KA. Characteristics of nontraumatic subarachnoid hemorrhage in the United States in 2003. Neurosurgery. 2007; 61: 1131-1138.

4. Molyneux AJ, Kerr R, Stratton I, Sandercock P, Clarke M, Shrimpton J, et al. International Subarachnoid Aneurysm Trial (ISAT) of neurosurgical clipping versus endovascular coiling in 2143 patients with ruptured intracranial aneurysms: a randomised trial. Lancet. 2002; 360: 1267-1274.

5. Spetzler RF, McDougall CG, Albuquerque FC, Zabramski JM, Hills NK, Partovi S, et al. The Barrow Ruptured Aneurysm Trial: 3-year results. J Neurosurg 2013; 119: 146-157. 
6. Bender MT, Wendt $\mathrm{H}$, Monarch $\mathrm{T}$, Lin LM, Jiang B, Huang J, et al. Shifting Treatment Paradigms for Ruptured Aneurysms from Open Surgery to Endovascular Therapy Over 25 Years. World Neurosurg. 2017.

7. Darsaut TE, Findlay JM, Magro E, Kotowski M, Roy D, Weill A et al. Surgica clipping or endovascular coiling for unruptured intracranial aneurysms: a pragmatic randomised trial. J Neurol Neurosurg Psychiatry. 2017; 88: 663 668

8. Drake CG. Report of world federation of neurosurgical surgeon committee on a universal SAH grading scale. J Neurosurg. 1988; 68: 985-986.

9. Patriota GC, da Silva-Júnior JM, Evangelista Santos Barcellos AC, de Sousa Silva Júnior J B, Oliveira Toledo D P, Campos Gomes Pinto F et al. Determining ICH Score: can we go beyond?. Arq Neuropsiquiatr. 2009; 67: 605-608.

10. Spagnuolo E, Quintana L. Hemorragia subaracnoidea por aneurisma cerebra roto. Guías de manejo clínico actualizadas 2010. Una propuesta al capítulo vascular de la FLANC. Rev Chil Neurocirugía. 2010; 35:72-86.

11. Burkhardt JK, Chua MHJ, Weiss M, Do ASS, Winkler EA, Lawton MT Risk of aneurysm residual regrowth, recurrence, and de novo aneurysm formation after microsurgical clip occlusion based on follow-up with catheter angiography. World Neurosurg. 2017; 106: 74-84.

12. Wiebers DO, Whisnant JP, Huston J $3^{\text {rd }}$, Meissner I, Brown RD Jr, Piepgras DG, et al. Unruptured intracranial aneurysms: natural history, clinical outcome, and risks of surgical and endovascular treatment. Lancet. 2003; 362: 103-110.

13. Patel BM, Ahmed A, Niemann D. Endovascular Treatment of Supraclinoid Internal Carotid Artery Aneurysms. Neurosurg Clin N Am. 2014; 25: 425-435.
14. Lacerda Gallardo AJ, Martín Chaviano D, Mirabal García Y, Quintana Záez J, Tacas Gil N. Microabordaje transciliar supraorbitario en la cirugía de aneurismas intracraneales de la circulación anterior. Rev Cubana Neurol Neurocir. 2014; 4: 130-135.

15. Cho WS, Kim JE, Kang HS, Son YJ, Bang JS, Oh CW. Keyhole Approach and Neuroendoscopy for Cerebral Aneurysms. J Korean Neurosurg Soc. 2017; 60: 275-281.

16. Mielke D, Malinova V, Rohde V. Comparison of intraoperative microscopic and endoscopic ICG angiography in aneurysm surgery. Neurosurgery. 2014; 10: $418-425$.

17. Cho WS, Kim JE, Kim SH, Kim HC, Kang U, Lee DS. Endoscopic fluorescence angiography with indocyanine green: a preclinical study in the swine. J Korean Neurosurg Soc. 2015; 58: 513-517.

18. Wali AR, Park CC, Santiago-Dieppa DR, Vaida F, Murphy JD, Khalessi AA. Pipeline embolization device versus coiling for the treatment of large and giant unruptured intracranial aneurysms: a cost-effectiveness analysis. Neurosurg Focus. 2017; 42: E6.

19. Valle-Giler EP, Atallah E, Tjoumakaris S, Rosenwasser RH, Jabbour P. Transcirculation Pipeline embolization device deployment: a rescue technique. Neurosurg Focus. 2017; 42: E13.

20. Silva MA, See AP, Dasenbrock HH, Patel NJ, Aziz-Sultan MA. Vision outcomes in patients with paraclinoid aneurysms treated with clipping, coiling, or flow diversion: a systematic review and meta-analysis. Neurosurg Focus. 2017; 42: E15.
Austin J Clin Case Rep - Volume 5 Issue 2 - 2018

ISSN : 2381-912X | www.austinpublishing group.com

Gallardo. () All rights are reserved
Citation: Gallardo AJL. Microsurgical Treatment of Intracranial Aneurysms: Report of a Series of Cases in a Single Cuban Hospital. Austin J Clin Case Rep. 2018; 5(2): 1132. 